\title{
Population-level interest in anti-rheumatic drugs in the COVID-19 era: insights from Google Trends
}

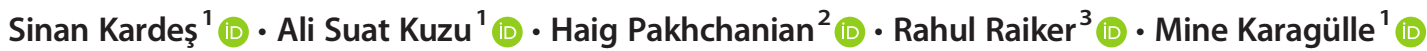

Received: 20 September 2020 / Revised: 21 October 2020 / Accepted: 28 October 2020 / Published online: 31 October 2020

(C) International League of Associations for Rheumatology (ILAR) 2020

\begin{abstract}
Introduction/objective The general public may utilize online information through search engines for implications and risks of some anti-rheumatic drugs. These drugs have been used in the management of coronavirus disease 2019 (COVID-19) and associated inflammatory sequelae or cytokine storm of infection. Therefore, the objective of this study was to investigate the population-level interest in anti-rheumatic drugs during the COVID-19 era, by analyzing changes in Google search frequency data.

Method To obtain the relative search volume (RSV) of anti-rheumatic drugs, we queried Google Trends for 78 search terms representing non-steroidal anti-inflammatory drugs (NSAIDs), glucocorticoids, antigout agents, conventional disease-modifying anti-rheumatic drugs (DMARDs), immunosuppressants, biologics, and Janus kinase (JAK) inhibitors within the USA. Three 8week periods in 2020 (March 15-May 9), (May 10-July 4), and (July 5-August 29) representing the initial- and short-term periods were compared to overlapping periods of the preceding 3 years (2017-2019).

Results We found statistically significant increases in RSV for colchicine, hydroxychloroquine, tocilizumab (and its brand nameActemra), and anakinra, and statistically significant decreases among brand names of immunosuppressive agents (i.e., mycophenolate mofetil, azathioprine, cyclophosphamide, tacrolimus, cyclosporine) during both the initial- and short-term COVID-19 periods as compared to overlapping periods of the preceding 3 years.

Conclusion There were significant increases in RSV of colchicine, hydroxychloroquine, tocilizumab, and anakinra during both initial- and short-term COVID-19 periods when compared to overlapping periods of the preceding 3 years reflecting a heightened level of information-seeking on these drugs during the pandemic. Rheumatologists should address this increase in informational demand. Further research assessing medium- and long-term interest in anti-rheumatic drugs is required to increase our knowledge on this new pandemic.

\section{Key Points}

- This study was aimed to investigate the population-level interest in anti-rheumatic drugs in the COVID-19 era, by analyzing changes in Google search frequency data.

- Significant increases were seen in relative searches for colchicine, hydroxychloroquine, tocilizumab, and anakinra during both initial and short-term COVID-19 periods when compared to similar periods of 2017-2019 reflecting a heightened level of information-seeking on these drugs during the pandemic.

- Rheumatologists should address this increase in informational demand for colchicine, hydroxychloroquine, tocilizumab, and anakinra.
\end{abstract}

Sinan Kardeș

sinan.kardes@istanbul.edu.tr

Ali Suat Kuzu

alisuatkuzu@gmail.com

Haig Pakhchanian

haig@gwmail.gwu.edu

Rahul Raiker

rsr0010@mix.wvu.edu

Mine Karagülle

mkgulle@ istanbul.edu.tr
1 Department of Medical Ecology and Hydroclimatology, Istanbul Faculty of Medicine, Istanbul University, Capa-Fatih, 34093 Istanbul, Turkey

2 George Washington University School of Medicine \& Health Science, Washington, DC, USA

3 West Virginia University School of Medicine, Morgantown, WV, USA 
Keywords Anakinra $\cdot$ Colchicine $\cdot$ Google search $\cdot$ Hydroxychloroquine $\cdot$ Internet $\cdot$ Tocilizumab

\section{Introduction}

Severe acute respiratory syndrome coronavirus 2 (SARS$\mathrm{CoV}-2$ ) is a novel coronavirus that emerged from Wuhan China in December 2019, causing the disease that is referred to as coronavirus disease 2019 (COVID-19). This disease spread rapidly throughout China and other regions of the world, resulting in the World Health Organization (WHO) declaring COVID-19 a pandemic [1]. Globally, a total of $28,329,790$ confirmed cases of COVID-19, including 911,877 deaths, had been reported to the WHO, as of September 12, 2020. The country with the highest number of cases and deaths is the USA, with 6,341,309 confirmed cases and 190,787 deaths [2].

Patients taking anti-rheumatic drugs share concerns regarding a potential increased risk of contracting COVID-19 infection [3-8], and the public may have searched online information for the implications and risks of some anti-rheumatic drugs, which have been used in the management of COVID19 infection and associated inflammatory sequelae or cytokine storm [9-15]. Therefore, population-level interest in antirheumatic drugs in the COVID-19 era should be investigated to increase our understanding of this new pandemic.

During the past decade, an increasing number of scientific studies have documented the importance of Google Trends in the detection of an epidemic and monitoring public interest [16-20]. It has been used to study previous epidemics such as influenza [21, 22], Dengue fever [23], and Zika virus [24]. In light of COVID-19, Google Trends data has been used to investigate population-level interest in several treatment approaches including urologic procedures [25], hip and knee arthroplasties [26], facial plastic surgery [27], and cosmetic procedures [28]. Furthermore, an interesting study investigating Google searches of hydroxychloroquine is available in the literature [29]. Our study would expand the knowledge on Google searches of anti-rheumatic drugs beyond hydroxychloroquine.

Therefore, we aimed to investigate the population-level interest in anti-rheumatic drugs in the COVID-19 era, by analyzing changes in Google search frequency data.

\section{Materials and method}

Google Trends presents the frequency of Google search terms in a normalized form as a relative search volume (RSV). Values of RSV range between 0 and 100, where 100 represents to the peak popularity for the search term [30]. The information on Google Trends and its data are presented in detail in the literature $[17,18]$.

We selected search terms that encompass anti-rheumatic drugs including non-steroidal anti-inflammatory drugs (NSAIDs), glucocorticoids, antigout agents, conventional Disease-modifying anti-rheumatic drugs (DMARDs), immunosuppressant agents, interleukin (IL)-6 inhibitors, IL-1 inhibitors, tumor necrosis factor (TNF) inhibitors, IL-17 inhibitors, IL-12/23 pathway targeting agents, T cell co-stimulation modulators, B cell-targeting agents, Janus kinase (JAK) inhibitors, and phosphodiesterase-4 (PDE4) inhibitor. Both generic and brand names of the drugs were included, and brand names were obtained from UpToDate [31]. We used a total of 78 search terms as the following: NSAIDs, Ibuprofen, Advil, Indomethacin, Indocin, Diclofenac, Voltaren, Naproxen, Aleve, Meloxicam, Mobic, Glucocorticoids, Prednisone, Deltasone, Colchicine, Colcrys + Mitigare, Allopurinol, Zyloprim, Febuxostat, Uloric, Hydroxychloroquine, Plaquenil, Methotrexate, Otrexup + Rasuvo + Rheumatrex + Trexall, Sulfasalazine, Azulfidine, Leflunomide, Arava, Mycophenolate mofetil, CellCept, Azathioprine, Imuran, Cyclophosphamide, Cytoxan, Tacrolimus, Prograf, Cyclosporine, Gengraf + Neoral + Sandimmune, Tocilizumab, Actemra, Sarilumab, Kevzara, Anakinra, Kineret, Canakinumab, Ilaris, Rilonacept, Arcalyst, Etanercept, Enbrel, Infliximab, Remicade, Adalimumab, Humira, Certolizumab, Cimzia, Golimumab, Simponi, Secukinumab, Cosentyx, Ixekizumab, Taltz, Ustekinumab, Stelara, Guselkumab, Tremfya, Abatacept, Orencia, Rituximab, Rituxan, Belimumab, Benlysta, Tofacitinib, Xeljanz, Baricitinib, Olumiant, Apremilast, and Otezla. To obtain the relative frequency of these selected search terms, we queried Google Trends with the selection of "United States," "01/01/2017-09/09/2020," and "Web Search" settings on September 9, 2020. We imposed no category restrictions when querying Google Trends and exported the Google Trends weekly RSV data for further analysis.

Search term RSV during the initial 8-week period (March 15-May 9, 2020), after US President Donald Trump declared a national emergency due to the COVID-19 outbreak, was compared with overlapping periods of the preceding 3 years (2017-2019) to investigate initial stage interest in the drugs. In addition, we compared May 10-July 4, 2020, and July 5-August 29, 2020, periods with overlapping periods in 2017-2019 to investigate short-term interest. Previous studies included the years of 2015 and 2016 as well [25, 26]; however, to avoid selection bias in our study, we excluded data from the years 2015 and 2016 because some antirheumatic drugs were less popular treatments during that time. 
To investigate whether RSV had changed between the periods, we performed generalized estimating equations using a model of gamma with log link. The analysis was conducted using SPSS version 21.0, IBM. The level of significance was established at the 0.05 level.

\section{Results}

During the initial period, March 15-May 9, 2020, the RSV of NSAIDs ( $\%$ change: $+88.4 \% ; p=0.030)$, diclofenac $(+7.7 \%$; $p=0.018)$, colchicine $(+24.4 \% ; p<0.001)$, febuxostat $(+$ $101.3 \% ; p<0.001)$, hydroxychloroquine $(+3613.0 \%$; $p<0.001)$, Plaquenil (+635.0\%; $p=0.003)$, tacrolimus (+ $12.6, p=0.030)$, tocilizumab $(+1253.5 \% ; p<0.001)$, Actemra $(+443.6 \% ; p<0.001)$, sarilumab $(+442.5 \%$; $p<0.001)$, Kevzara $(+272.2 \% ; p<0.001)$, anakinra $(+$ $188.6 \% ; p<0.001)$, infliximab $(+19.2 \% ; p=0.005)$, Stelara $(+13.8 \% ; p=0.015)$, and baricitinib $(+91.9 \% ; p=0.027)$ showed a statistically significant increase; conversely, the RSV of Indocin $(-39.4 \% ; p<0.001)$, Voltaren $(-26.2 \%$; $p<0.001)$, meloxicam $(-6.5 \% ; p=0.012)$, Mobic $(-38.9 \%$; $p<0.001)$, allopurinol $(-12.6 \% ; p=0.006)$, Zyloprim ($27.6 \% ; p=0.034)$, Uloric $(-39.9 \% ; p<0.001)$, methotrexate $(-12.6 \% ; p<0.001)$, Arava $(-29.3 \% ; p<0.001)$, CellCept $(-15.4 \% ; p=0.003)$, Imuran $(-31.5 \% ; p<0.001)$, Cytoxan $(-24.5 \% ; p<0.001)$, Prograf $(-31.1 \% ; p<0.001)$, Gengraf + Neoral + Sandimmune $(-28.0 \% ; p=0.026)$, canakinumab ($1.3 \% ; p=0.046)$, Ilaris $(-32.5 \% ; p=0.029)$, rilonacept $(-$ $14.2 \% ; p=0.023)$, Remicade $(-12.0 \% ; p=0.031)$, golimumab $(-37.2 \% ; p=0.005)$, ixekizumab $(-32.7 \% ; p=$ $0.008)$, Taltz $(-30.7 \% ; p<0.001)$, and Rituxan $(-34.4 \%$; $p<0.001)$ displayed a statistically significant decrease as compared to overlapping periods of the preceding 3 years (Table 1).

During the May 10-July 4, 2020, period, Diclofenac (+ $14.8 \% ; p<0.001)$, Voltaren $(+222.8 \% ; p<0.001)$, Febuxostat $(+72.3 \% ; p<0.001)$, Hydroxychloroquine (+ $1375.0 \% ; p=0.017)$, Sulfasalazine $(+20.0 \% ; p=0.010)$, Azathioprine $(+11.6 \% ; p=0.055)$, Tocilizumab $(+434.4 \%$; $p<0.001)$, Actemra $(+87.1 \% ; p<0.001)$, Anakinra $(+$ 91.0\%; $p<0.001)$, Arcalyst $(+36.7 \% ; p=0.049)$, Baricitinib $(+153.2 \% ; p<0.001)$, and Olumiant $(+42.8 \% ; p=0.039)$ showed a statistically significant increase; conversely, Advil $(-8.6 \% ; p<0.001)$, Indomethacin $(-10 \% ; p=0.023)$, Indocin $(-21.7 \% ; p=0.006)$, Naproxen $(-8.3 \% ; p<0.001)$, Aleve $(-11.8 \% ; p<0.001)$, Mobic $(-26.3 \% ; p<0.001)$, Prednisone $(-7.2 \% ; p=0.018)$, Methotrexate $(-6.6 \% ; p=$ $0.071)$, Sulfasalazine $(+20.0 \% ; p=0.010)$, Arava $(-20.6 \%$; $p=0.010)$, CellCept $(-21.9 \% ; p<0.001)$, Imuran $(-22.5 \%$; $p<0.001)$, Cytoxan $(-20.4 \% ; p<0.001)$, Gengraf + Neoral + Sandimmune $(-29.1 \% ; p<0.001)$, Etanercept $(-24.7 \% ; p=$ $0.029)$, Enbrel $(-24.8 \% ; p=0.004)$, Remicade $(-24.6 \%$; $p<0.001)$, Humira $(-15.4 \% ; p=0.002)$, Golimumab ($40.0 \% ; p=0.002)$, Simponi $(-12.3 \% ; p=0.042)$, Taltz ($21.6 \% ; p=0.004)$, Rituxan $(-25.0 \% ; p<0.001)$, and Tofacitinib $(-22.0 \% ; p=0.012)$ displayed a statistically significant decrease compared to preceding 3 years (Table 1 ).

During the July 5-August 29, 2020, period, Ibuprofen (+ $6.7 \% ; p=0.015)$, Advil $(+3.4 \% ; p=0.036$, Diclofenac $(+$ $11.6 \% ; p<0.001)$, Voltaren $(+118.8 \% ; p<0.001)$, Glucocorticoids $(+22.3 \% ; p=0.021)$, Colchicine $(+17.1 \%$; $p<0.001)$, Febuxostat $(+63.3 \% ; p<0.001)$, Hydroxychloroquine $(+2125.0 \% ; p=0.046)$, Tacrolimus $(+$ $18.2 \% ; p=0.005)$, Tocilizumab $(+400.0 \% ; p<0.001)$, Actemra $(+61.5 \% ; p<0.001)$, Anakinra $(+71.2 \%$; $p<0.001)$, Infliximab $(+32.6 \% ; p<0.001)$, Tremfya $(+$ $24.0 \% ; p=0.017)$, and Baricitinib $(+88.2 \% ; p<0.001)$ showed a statistically significant increase; conversely, Indocin $(-26.0 \% ; p<0.001)$, Naproxen $(-8.5 \% ; p<0.001)$, Aleve $(-7.7 \% ; p=0.004)$, Mobic $(-20.6 \% ; p<0.001)$, Uloric $(-45.3 \% ; p<0.001)$, CellCept $(-13.2 \% ; p=0.023)$, Imuran $(-19.2 \% ; p=0.003$, Cytoxan $(-21.5 \% ; p=0.005)$, Cyclosporine $(-7.8 \% ; p=0.021)$, Gengraf + Neoral + Sandimmune $(-29.9 \% ; p=0.018)$, Arcalyst $(-43.4 \%$; $p<0.001)$, Enbrel $(-19.6 \% ; p<0.001)$, Remicade ($19.0 \% ; p<0.001)$, Humira $(-11.0 \% ; p=0.010)$, Certolizumab $(-27.8 \% ; p=0.027)$, Secukinumab $(-27.7 \%$; $p=0.039)$, Cosentyx $(-14.2 \% ; p=0.011)$, Ixekizumab ($29.6 \% ; p=0.005)$, Rituxan $(-22.1 \% ; p<0.001)$, and Tofacitinib $(-26.8 \% ; p=0.012)$ displayed a statistically significant decrease compared to preceding 3 years (Table 1 ).

\section{Discussion}

We found statistically significant increases in RSV for colchicine, hydroxychloroquine, tocilizumab (and its brand nameActemra), and anakinra, and statistically significant decreases among brand names of immunosuppressive agents (i.e., mycophenolate mofetil, azathioprine, cyclophosphamide, tacrolimus, and cyclosporine) during both the initial- and short-term COVID-19 periods as compared to overlapping periods of the preceding 3 years.

In a previous study investigating Google searches indicative of increased purchases of chloroquine and hydroxychloroquine, Liu et al. showed that demand for chloroquine and hydroxychloroquine increased following endorsements by Elon Musk and President Donald Trump [29]. In our study, we detected a statistically significant increase in RSV of hydroxychloroquine in all three periods investigated, indicating continued interest in hydroxychloroquine by the general public.

Aside from hydroxychloroquine, we showed an increased interest in colchicine, tocilizumab, and anakinra in both initial and short terms of COVID-19. The increased public interest in 


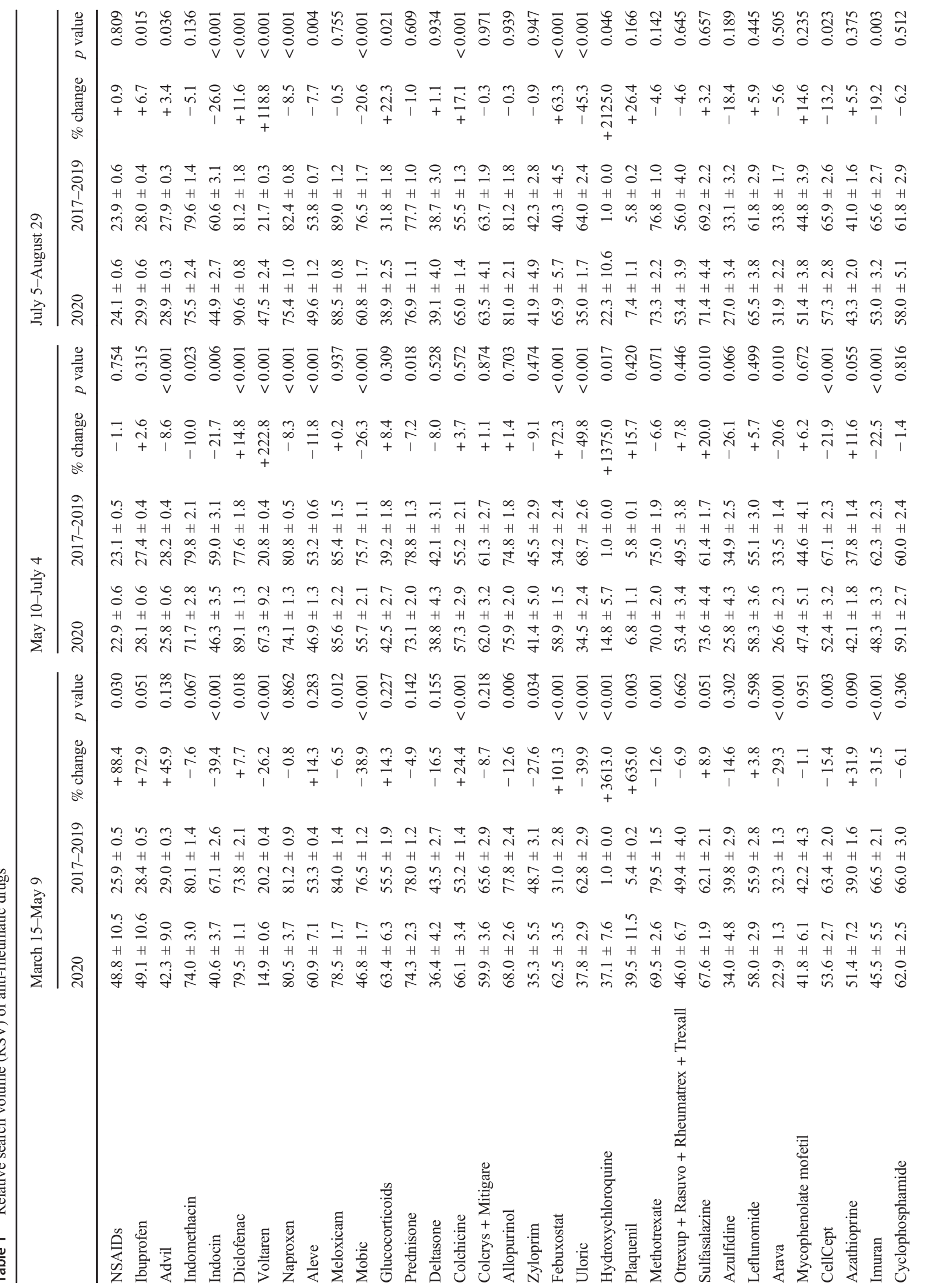




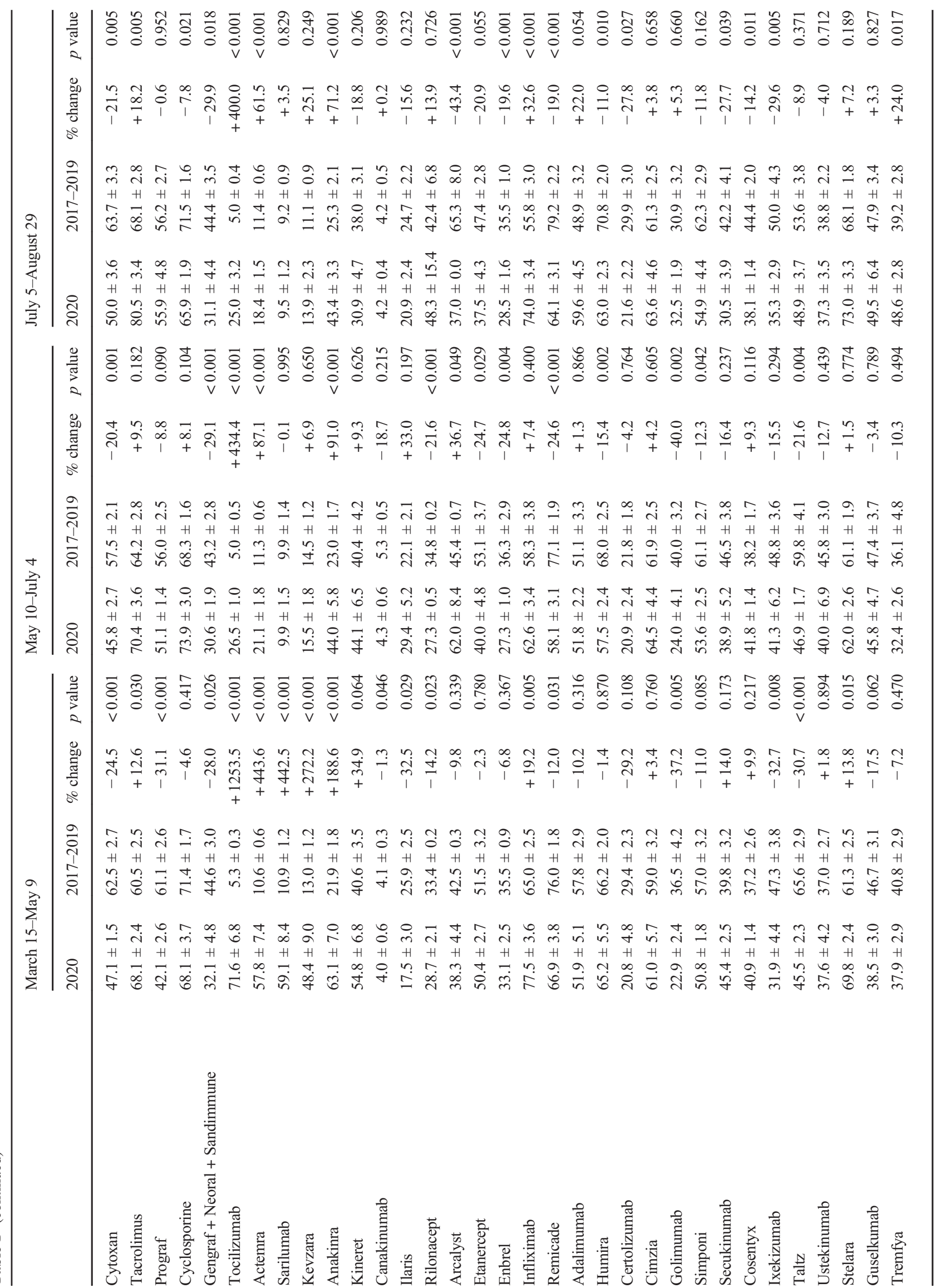




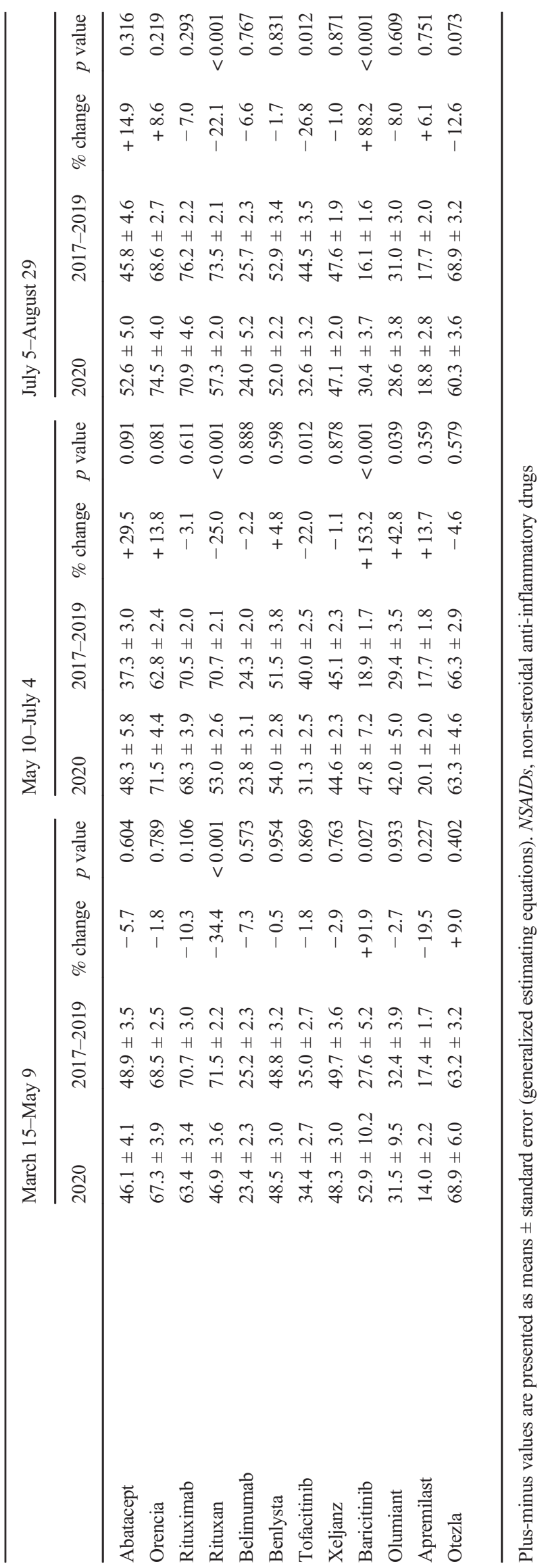


colchicine, tocilizumab, and anakinra may be attributed to media coverage of scientific studies investigating these drugs as potential therapeutic agents for the COVID-19 [32-37]. This finding also indicates that the general public has informational needs for these drugs. Given that the evidence on their efficacy, safety, or use for COVID-19 has been evolving, we recommend readers to refer to the recent version of National Institutes of Health (NIH) and Infectious Diseases Society of America (IDSA) treatment guidelines regarding the treatment and management of COVID-19 [14, 15].

In the initial period (March 15-May 9, 2020), the RSV of the term "NSAIDs" showed a statistically significant increase in RSV. Although statistically insignificant, the RSV of ibuprofen has also increased $73 \%$ in this period compared to the preceding 3 years. Between March and April 2020, the WHO provided a series of recommendations for the use of NSAIDs to treat COVID-19 that garnered public attention. In March 2020, the WHO initially advised against using ibuprofen to treat COVID-19 [38]; however, they later updated its recommendation by tweeting, "based on currently available information, WHO does not recommend against the use of ibuprofen" [39]. In April 2020, WHO published an overview on the use of NSAIDs in patients with COVID-19 [40]. Therefore, the initial trends observed in NSAIDs searches might be due to the discussions on the use of NSAIDs in patients with COVID-19.

It is notable that the RSV of brand names of immunosuppressive agents (i.e., mycophenolate mofetil, azathioprine, cyclophosphamide, tacrolimus, and cyclosporine) was reduced during the COVID-19 period compared to 2017-2019. It can be speculated that these agents have been initiated/added to the treatment regimens of patients with a rheumatic disease less often during the COVID-19 period, as these drugs have previously been associated with an increased risk of certain viral infections [41]. However, this assumption needs further validation. The more likely explanation for the observed decrease is that these drugs were initiated/prescribed less frequently during the COVID-19 period due to a general decrease in transplant surgeries [42] as these drugs are also used to prevent tissue rejection after an organ transplant. The decrease in the initiation of these drugs may lead to an observed decrease in RSV of these drugs, as patients who were prescribed a new immunosuppressive drug may search for online information. This presumption requires confirmation as well. Additionally, to our knowledge, it should be noted that there is currently no evidence on a possible association between an increased risk of COVID-19 and these immunosuppressive agents. Furthermore, the American College of Rheumatology (ACR) guidelines regarding the management of rheumatic diseases during the COVID-19 pandemic (version 2) recommend that conventional (DMARDs), immunosuppressants, biologics, JAK inhibitors, and NSAIDs may be continued in patients with stable rheumatic disease in the absence of COVID-19 infection or SARS-CoV-2 exposure [9]. However, as the literature is rapidly evolving, we recommend readers to refer to the recent version of ACR, European League Against Rheumatism (EULAR), and African League Against Rheumatism (AFLAR) guidelines on the management of rheumatic diseases during the COVID-19 pandemic $[9,10,43]$.

Previous studies investigated the population-level interest in several treatment approaches during the COVID-19 era [25-28]. Bhambhvani et al. examined the population-level interest in elective urology procedures categorized into 4 categories: male infertility, erectile dysfunction, Peyronie's disease, and vasectomy. They showed a decrease across all categories in the 30 days prior to March 18, 2020, period compared to 30 days after and March-May 2020 period compared to January 2015-February 2020 [25]. Jella et al. showed a decrease in population-level interest in knee and hip arthroplasties during March 2020, which breeched the lower control limit of previous 5 years [26]. In a study investigating population-level interest in facial plastic surgery from January 1, 2020, to July 10, 2020, Dhanda et al. showed a significant decrease during March-April 2020 compared to JanuaryFebruary 2020 [27]. Guzman and Barbieri examined the population-level interest in cosmetic procedures. They showed a statistically significant decrease in March 15-29, 2020, period compared to April 28, 2019,-March 8, 2020 (pre-pandemic period) [28]. All these previous studies showed a decrease in interest in treatment approaches investigated. Distinct from these previous studies investigating the procedural treatments, our study investigated pharmacological treatments (i.e., anti-rheumatic drugs). Also, as our study was conducted later, it was able to include a wider period of 2020. Therefore, it provides information not only on initial stage but also on short-term interest.

\section{Limitations}

Our study has some limitations. We used Google Trends, which captures the search behavior of people using the Google search engine, exclusively. However, it most likely represents American search queries because the Google search engine accounts for over $85 \%$ of all internet search volume in the USA [44]. Furthermore, because Google Trends does not provide demographic characteristics of the people who search on Google, the interest cannot be assessed by stratifying specific subpopulations. Therefore, our results can only be applied to the general population. Also, to control for possible seasonal variation in the searches $[18,20]$, we compared the COVID-19 period to preceding years (as similarly performed in previous studies [25, 26]); however, this approach may also introduce a limitation. The observed differences might be caused by decreases/increases in searches in 
2017-2019 (e.g., Food and Drug Administration warning on Uloric in 2019 [45]). Therefore, our results should be interpreted with caution and need to be verified by further studies. Despite these limitations, our study would contribute to the knowledge on Google searches of anti-rheumatic drugs during the COVID-19 pandemic.

\section{Conclusion}

There were significant increases in RSV of colchicine, hydroxychloroquine, tocilizumab, and anakinra during both initial and short-term COVID-19 periods when compared to overlapping periods of the preceding 3 years reflecting a heightened level of information-seeking on these drugs during the pandemic. Rheumatologists should address this increase in informational demand. Further research assessing mediumand long-term interests in anti-rheumatic drugs is required to increase our knowledge on this new pandemic.

Authors' contributions Conception of the study: SK; collection, analysis, and/or interpretation of data: SK, ASK, HP, RR, and MK; drafting the manuscript: SK; critically revising and editing the manuscript: SK, ASK, HP, RR, and MK; final approval for submission: SK, ASK, HP, RR, and MK.

Data availability The data are available from the corresponding author on reasonable request.

\section{Compliance with ethical standards}

Conflict of interest SK received congress travel, accommodation, and participation fee support (12th Anatolian Rheumatology Days) from Abbvie. The other authors have no conflict of interest in this study.

\section{Ethics approval NA}

Consent to participate NA

Consent for publication NA

\section{References}

1. World Health Organization announces COVID-19 outbreak a pandemic. https://www.euro.who.int/en/health-topics/healthemergencies/coronavirus-covid-19/news/news/2020/3/whoannounces-covid-19-outbreak-a-pandemic/. Accessed 12 Sept 2020

2. World Health Organization. https://covid19.who.int/. Accessed 12 Sept 2020

3. Ladani AP, Loganathan M, Danve A (2020) Managing rheumatic diseases during COVID-19. Clin Rheumatol 39:3245-3254. https://doi.org/10.1007/s10067-020-05387-8

4. Montero F, Martínez-Barrio J, Serrano-Benavente B, González T, Rivera J, Molina Collada J, Castrejón I, Álvaro-Gracia J (2020) Coronavirus disease 2019 (COVID-19) in autoimmune and inflammatory conditions: clinical characteristics of poor outcomes.
Rheumatol Int 40:1593-1598. https://doi.org/10.1007/s00296020-04676-4

5. Coskun Benlidayi I, Kurtaran B, Tirasci E, Guzel R (2020) Coronavirus disease 2019 (COVID-19) in a patient with ankylosing spondylitis treated with secukinumab: a case-based review. Rheumatol Int 40:1707-1716. https://doi.org/10.1007/s00296020-04635-Z

6. Haslak F, Yildiz M, Adrovic A, Sahin S, Koker O, Aliyeva A, Barut K, Kasapcopur O (2020) Management of childhood-onset autoinflammatory diseases during the COVID-19 pandemic. Rheumatol Int 40:1423-1431. https://doi.org/10.1007/s00296020-04645-x

7. Kastritis E, Kitas GD, Vassilopoulos D, Giannopoulos G, Dimopoulos MA, Sfikakis PP (2020) Systemic autoimmune diseases, anti-rheumatic therapies, COVID-19 infection risk and patient outcomes. Rheumatol Int 40:1353-1360. https://doi.org/10. 1007/s00296-020-04629-x

8. Seyahi E, Poyraz BC, Sut N, Akdogan S, Hamuryudan V (2020) The psychological state and changes in the routine of the patients with rheumatic diseases during the coronavirus disease (COVID19) outbreak in Turkey: a web-based cross-sectional survey. Rheumatol Int 40:1229-1238. https://doi.org/10.1007/s00296020-04626-0

9. Mikuls TR, Johnson SR, Fraenkel L, Arasaratnam RJ, Baden LR, Bermas BL, Chatham W, Cohen S, Costenbader K, Gravallese EM, Kalil AC, Weinblatt ME, Winthrop K, Mudano AS, Turner A, Saag KG (2020) American College of rheumatology guidance for the management of rheumatic disease in adult patients during the COVID-19 pandemic: version 2. Arthritis Rheumatol 72. https:// doi.org/10.1002/art.41437

10. Landewé RB, Machado PM, Kroon F, Bijlsma HW, Burmester GR, Carmona L et al (2020) EULAR provisional recommendations for the management of rheumatic and musculoskeletal diseases in the context of SARS-CoV-2. Ann Rheum Dis 79:851-858. https://doi. org/10.1136/annrheumdis-2020-217877

11. Misra DP, Gasparyan AY, Zimba O (2020) Benefits and adverse effects of hydroxychloroquine, methotrexate and colchicine: searching for repurposable drug candidates. Rheumatol Int 40: 1741-1751. https://doi.org/10.1007/s00296-020-04694-2

12. Misra DP, Agarwal V, Gasparyan AY, Zimba O (2020) Rheumatologists' perspective on coronavirus disease 19 (COVID-19) and potential therapeutic targets. Clin Rheumatol 39:2055-2062. https://doi.org/10.1007/s10067-020-05073-9

13. Schrezenmeier EV, Burmester GR, Eckardt KU, Dörner T (2020) Role for antimalarials in the management of COVID-19. Curr Opin Rheumatol 32:449-457. https://doi.org/10.1097/BOR. 0000000000000731

14. Bhimraj A, Morgan RL, Shumaker AH, Lavergne V, Baden L, Cheng VC et al (2020) Infectious Diseases Society of America guidelines on the treatment and management of patients with COVID-19. Clin Infect Dis. https://doi.org/10.1093/cid/ciaa478

15. National Institutes of Health. Coronavirus disease 2019 (COVID19) treatment guidelines. https://covid19treatmentguidelines.nih. gov/. Accessed 12 Sept 2020

16. Eysenbach G (2009) Infodemiology and infoveillance: framework for an emerging set of public health informatics methods to analyze search, communication and publication behavior on the Internet. J Med Internet Res 11:e11. https://doi.org/10.2196/jmir.1157

17. Mavragani A, Ochoa G (2019) Google Trends in infodemiology and infoveillance: methodology framework. JMIR Public Health Surveill 5:e13439. https://doi.org/10.2196/13439

18. Kardeș S (2019) Seasonal variation in the internet searches for gout: an ecological study. Clin Rheumatol 38:769-775. https://doi.org/ 10.1007/s10067-018-4345-2

19. Martinez-Arroyo G, Ramos-Gomez S, Rojero-Gil EK, RojasGongora JA, Barajas-Ochoa A, Bustamante-Montes LP, Yañez J, 
Ramos-Remus C (2019) Potential uses of an infodemiology approach for health-care services for rheumatology. Clin Rheumatol 38:869-876. https://doi.org/10.1007/s10067-018-4364-z

20. Kardeş S (2019) Seasonal variation in the internet searches for psoriasis. Arch Dermatol Res 311:461-467. https://doi.org/10. 1007/s00403-019-01921-0

21. Ginsberg J, Mohebbi MH, Patel RS, Brammer L, Smolinski MS, Brilliant L (2009) Detecting influenza epidemics using search engine query data. Nature 457:1012-1014. https://doi.org/10.1038/ nature 07634

22. Olson DR, Konty KJ, Paladini M, Viboud C, Simonsen L (2013) Reassessing Google Flu Trends data for detection of seasonal and pandemic influenza: a comparative epidemiological study at three geographic scales. PLoS Comput Biol 9:e1003256. https://doi.org/ 10.1371/journal.pcbi.1003256

23. Yang S, Kou SC, Lu F, Brownstein JS, Brooke N, Santillana M (2017) Advances in using Internet searches to track dengue. PLoS Comput Biol 13:e1005607. https://doi.org/10.1371/journal.pcbi. 1005607

24. Teng Y, Bi D, Xie G, Jin Y, Huang Y, Lin B, An X, Feng D, Tong Y (2017) Dynamic forecasting of Zika epidemics using Google trends. PLoS One 12:e0165085. https://doi.org/10.1371/journal. pone. 0165085

25. Bhambhvani HP, Tijerina JD, Parham MJ, Greenberg DR, Eisenberg ML (2020) Public interest in elective urologic procedures in the COVID-19 pandemic: a Google Trends analysis. Urol Pract 7:496-501. https://doi.org/10.1097/UPJ. 0000000000000179

26. Jella TK, Samuel LT, Acuña AJ, Emara AK, Kamath AF (2020) Rapid decline in online search queries for hip and knee arthroplasties concurrent with the COVID-19 pandemic. J Arthroplast 35:2813-2819. https://doi.org/10.1016/j.arth.2020.05. 051

27. Dhanda AK, Leverant E, Leshchuk K, Paskhover B (2020) A Google Trends analysis of facial plastic surgery interest during the COVID-19 pandemic. Aesthet Plast Surg 44:1378-1380. https://doi.org/10.1007/s00266-020-01903-y

28. Guzman AK, Barbieri JS (2020) Analysis of dermatology-related search engine trends during the COVID-19 pandemic: implications for patient demand for outpatient services and telehealth. J Am Acad Dermatol 83:963-965. https://doi.org/10.1016/j.jaad.2020. 05.147

29. Liu M, Caputi TL, Dredze M, Kesselheim AS, Ayers JW (2020) Internet searches for unproven COVID-19 therapies in the United States. JAMA Intern Med 180:1116-1118. https://doi.org/10.1001/ jamainternmed.2020.1764

30. Google Trends. https://trends.google.com/trends/. Accessed 9 Sept 2020

31. https://www.uptodate.com/. Accessed 7 Sept 2020

32. Carbone C. New trial to test if anti-inflammatory drug colchicine prevents COVID-19 complications. https://www.foxnews.com/ science/at-home-study-to-test-if-common-drug-prevents-covid-19complications/. Accessed 13 Sept 2020

33. Hein A. Gout medication eyed as possible coronavirus treatment by researchers. https://www.foxnews.com/health/gout-medication- eyed-possible-coronavirus-treatment-by-researchers/. Accessed 13 Sept 2020

34. Rivas K. Tocilizumab drug shows coronavirus treatment promise, doctor says. https://www.foxnews.com/health/tocilizumab-drugshows-coronavirus-treatment-promise-doctor-says/. Accessed 13 Sept 2020

35. Mandavilli A. The coronavirus patients betrayed by their own immune systems. https:/www.nytimes.com/2020/04/01/health/ coronavirus-cytokine-storm-immune-system.html/. Accessed 13 Sept 2020

36. Dominus S. The Covid drug wars that pitted doctor vs. doctor. https://www.nytimes.com/2020/08/05/magazine/covid-drug-warsdoctors.html/. Accessed 13 Sept 2020

37. Boseley S. Recovery trial for Covid-19 treatments: what we know so far. https://www.theguardian.com/world/2020/jun/16/recoverytrial-for-covid-19-treatments-what-we-know-so-far/. Accessed 13 Sept 2020

38. Moore N, Carleton B, Blin P, Bosco-Levy P, Droz C (2020) Does ibuprofen worsen COVID-19? Drug Saf 43:611-614. https://doi. org/10.1007/s40264-020-00953-0

39. https://twitter.com/WHO/status/1240409217997189128/. Accessed 13 Sept 2020

40. World Health Organization. The use of non-steroidal anti-inflammatory drugs (NSAIDs) in patients with COVID-19. https://www. who.int/publications/i/item/the-use-of-non-steroidal-antiinflammatory-drugs-(nsaids)-in-patients-with-covid-19/. Accessed 13 Sept 2020

41. Furer V, Rondaan C, Heijstek M, van Assen S, Bijl M, AgmonLevin N, Breedveld FC, D'Amelio R, Dougados M, Kapetanovic MC, van Laar JM, Ladefoged de Thurah A, Landewé R, Molto A, Müller-Ladner U, Schreiber K, Smolar L, Walker J, Warnatz K, Wulffraat NM, Elkayam O (2019) Incidence and prevalence of vaccine preventable infections in adult patients with autoimmune inflammatory rheumatic diseases (AIIRD): a systemic literature review informing the 2019 update of the EULAR recommendations for vaccination in adult patients with AIIRD. RMD Open 5: e001041. https://doi.org/10.1136/rmdopen-2019-001041

42. Grady D. The pandemic's hidden victims: sick or dying, but not from the virus. https://www.nytimes.com/2020/04/20/health/ treatment-delays-coronavirus.html/. Accessed 13 Sept 2020

43. Akintayo RO, Bahiri R, El Miedany Y, Olaosebikan H, Kalla AA, Adebajo AO et al (2020) African League Against Rheumatism (AFLAR) preliminary recommendations on the management of rheumatic diseases during the COVID-19 pandemic. Clin Rheumatol. https://doi.org/10.1007/s10067-020-05355-2

44. Statcounter. https://gs.statcounter.com/search-engine-marketshare/. Accessed 13 Sept 2020

45. FDA adds Boxed Warning for increased risk of death with gout medicine Uloric (febuxostat). https://www.fda.gov/drugs/drugsafety-and-availability/fda-adds-boxed-warning-increased-riskdeath-gout-medicine-uloric-febuxostat/. Accessed 13 Sept 2020

Publisher's note Springer Nature remains neutral with regard to jurisdictional claims in published maps and institutional affiliations. 